developing star ratings for those roads, with the ultimate goal of eliminating one- and two-star rated roads from the world's road network. 3 primary schools were selected in South Africa where intervention took place and 1 school served as a control for monitoring and evaluation purposes.

Results The pilot project has developed an innovative model combining education for the school children, training for teachers and advocacy action to catalyse the introduction of safe road infrastructure. It has also enabled creation of a multi-stakeholder partnership and further contributed to development of educational tool kit by Takalani Sesame (Sesame Street).

The project has been successful in one of its primary objectives to encourage the government to ensure sustained investments for safer roads thorough collaboration with City of Cape Town road engineers.

Conclusion The project has been effective as a model for catalysing sustainable investment in interventions aimed to improve road safety for school children. This model has the potential to be replicated on a wider basis across other schools in South Africa and other countries.. With its outcomes and potential long term impact, it has already made valuable contribution to the Decade of Action for Road Safety and has the potential to do so.

\section{THE SOCIAL DETERMINANTS OF TRAFFIC-RELATED INJURIES AMONG ADOLESCENTS}

1,2 Mohamed Mouloud Haddak. 'University of Lyon, France; ${ }^{2}$ Ifsttar-Umreste, France

10.1136/injuryprev-2016-042156.886

Background Youngster injury is the leading cause of mortality, morbidity and permanent disability in adolescent in the developed world. The objective of this research is to study the joint effect of family and contextual socioeconomic characteristics of teenagers on their risk of road accidents, taking into account their mobility practices, their behaviour and their attitude to risk.

Methods A case-control study was conducted on a population of 601 young people aged 14-17, in 2013. Cases (208 subjects) were selected from the Rhône Road Trauma Registry. Controls (393 subjects) adjusted by age and sex were randomly selected by telephone. L'exposition à la circulation routière est mesurée pour chaque mode de transport utilisé par le budget-temps. The relationships between SES status, urban/periurban-rural location, mode of transport, mobility practice, and injury type were determined using conditional logistic regression. Exposure to road traffic is measured for each mode of transportation used by the weekly time budget.

Results The intensive use of motorised two-wheelers holds an essential role in the risk of road accidents between 14 and 17 years $(\mathrm{OR}=4.1[2.3-7.2])$, followed by regular cycling $(\mathrm{OR}=3.6[2.0-6.5])$ and skating $(\mathrm{OR}=1.9$ [1.1-3.1]). Socioeconomic status of young people is highlighted: students in professional college or young apprentices are at higher risk $(\mathrm{OR}=2.1[1-4.3])$. Compared with urban adolescents, adolescents living in rural areas suffer a 1.9 higher risk (1.9 [1.2-3.0]). The links between road risk behaviour and smoking are also underlined (OR $=4.4$ [2-9.7]).

Conclusions These results show that adolescent road traffic injury in Rhône is a major health concern, especially among motorcyclist males (40\% of the injuries) from rural area and from lower SES. But this study also shows the significant impact of behavioural factors (tobacco, cannabis) on the risk of accident.

\section{ANALYSING THE OFFENDER DRIVER BEHAVIOUR: RECIDIVISM, JUST THE TIP OF THE ICEBERG?}

${ }^{1} \mathrm{C}$ Castro, ${ }^{1} \mathrm{~A}$ Gugliotta, ${ }^{1} \mathrm{P}$ García-Fernández, ${ }^{2} \mathrm{P}$ Ventsislavova, ${ }^{1} \mathrm{E}$ Esiman, ${ }^{2} \mathrm{D}$ Crundall. ${ }^{1}$ University of Granada, Spain; ${ }^{2}$ Nottingham Trent University, UK

\subsection{6/injuryprev-2016-042156.887}

Background The Subjective Risk Estimation (SER) depends on the own driving skills self- assessment and the calibration made between the benefits and cost involved in this risk at the moment of driving. Offender drivers' assumption of higher risk could be related with a more general factor that also involves the assumption of higher risk in other facets of their lives that could derive in drugs taking or other kind of additions. Deficient SER could be considered as a TRAIT, a higher proneness or disposition that only some drivers could show as another characteristic of their personality (measured with the DOSPERT (Domain-Specific Risk Taking). It could also be possible to establish a relation with other personality measures related to Anger or Aggressive Driving, measured with DAS (Driving Anger Scale).

Methods The Subjective Risk Estimation (SER) is measured with the DOSPERT (Domain-Specific Risk Taking Scale). The Anger to Aggressive Driving is measured with DAS (Driving Anger Scale).

Results In this work we would like to find out if could deficient SER be considered as a TRAIT of personality and some drivers could show a higher proneness to it (i.e. offender drivers) and if does deficient SER take part of a more general pattern of behaviour related with risk behaviour (drugs taking, alcohol consumption, and addiction to food or sex) that should be also trait to sort the problem out. Results are in progress.

Conclusions This knowledge could be useful to better understand the different profiles of drivers. To plan prevention and to settle better strategies of intervention and treatment of the specific lacks for each group of drivers, for instance, reducing aggressive driving or helping to be aware of the problem and dealing with the Anger in offender drivers.

\section{\begin{tabular}{|l|l}
888 & ROAD TRAFFIC INJURIES IN CROATIA
\end{tabular}}

Ivana Brkic Bilos, Maja Silobrcic Radic, Verica Kralj, Tanja Coric. Croatian Institute of Public Health, Croatia

\subsection{6/injuryprev-2016-042156.888}

Background The objective of this paper was to analyse mortality and morbidity from road traffic injuries in Croatia, as a contribution to the awareness of this public health.

Methods The data used in the research was collected from the routine mortality and morbidity statistics, Ministry of Interior Data, European Health for All Database, as well as from the results of the Global Status Report on Road Safety 2015 (GSRRS).

Results Traffic accidents and their consequences are still a serious public health problem in Croatia. They are the leading cause of child and youth mortality and the leading cause of premature deaths within the injuries group. Croatia has lately reported a noteworthy drop in road fatalities, despite the increase in number of drivers, motor vehicles and roads. According to the Ministry of Interior data, the road traffic injury (RTI) mortality rate for Croatia in 2005 was $13.4 / 100.000$, only to drop to $7.3 / 100.000$ in 2014. Injuries incurred in traffic accidents account for $21.3 \%$ of all injury-related hospitalizations in 2014. Croatia has achieved sustained reductions in traffic-related injuries and fatalities through effective road safety program and good level of 
enforcement of legislative related to the five key risk factors for road traffic injuries which was investigated in GSRRS: speed, drink-driving, failure to use motorcycle helmets, seat-belts and child restraints. Since 1994, Croatia has implemented the National Road Safety Program, and in April of 2011 the same national draft program was adopted for the 2011-2020 period. The primary objective of the National Road Safety Program is to halve the number of road deaths by 2020 .

Conclusions Though significant progress has been achieved in road safety, more systematic work will be dedicated to elevating the level of road safety in line with international initiatives and national guidelines.

\section{AN ANALYSIS OF CAR CRASHES FATALITIES INVOLVING YOUNG DRIVERS IN QUEENSLAND AUSTRALIA}

Florin Oprescu, Bridie Scott-Parker, Jeanne Dayton. University of the Sunshine Coast

\subsection{6/injuryprev-2016-042156.889}

Background The road safety of children and young adults is an important topic across the globe due to the significant loss of life in this population due to road crash fatalities. To inform preventative interventions directed at high risk population it is important to explore the characteristics of fatal accidents involving young passengers and drivers.

Methods In Queensland, Australia, the Commission for Children and Young People and Child Guardian collects data pertaining to every registered child death ( $<18$ years), including deaths due to road crashes. Data for the period 1 July 2004 to 30 June 2012 was analysed with regards to demographic factors and variables such as age, gender, driver licence status and socioeconomic status, in order to provide insights into risk factors associated with traffic related child deaths where a driver 21 years or younger was involved.

Results Between 2004-2012, 100 children aged $<18$ years died in a road crash in Queensland where the driver was 21 years or younger, amounting to a total of 6283.5 disability adjusted life years. Risk factors included being male, living in a socioeconomically-disadvantaged location, driving inexperience and driving on the road before licensed. Ninety percent of fatalities were in the 15-17 years group and $68 \%$ of fatalities were male, suggesting gender-focused interventions that target male children, youth, and their parents deserve additional resourcing, especially in low resource areas. There is a clear need to engage youth and parents more broadly to reduce the risks associated with unlicensed driving, and to ensure that these youth have access to and are engaged with relevant programs in order to gain the maximum road safety benefits for themselves, their passengers, and other road users.

Conclusion Knowledge regarding contributors to and characteristics of crashes are vital for intervention efforts that prevent crash involvement of young people. For children to be safe on the road, the wider system which supports, regulates, and encourages their safety needs to operate effectively. Additional attention should be focused on environmental factors such as socio economic status and other social determinants of health in addition to driver-specific factors.

\section{0 "SEE ME SAVE ME" - IMPROVING THE SAFETY OF CYCLISTS}

Harpreet Singh Dhunna. Founder President Avoid Accident, India

\subsection{6/injuryprev-2016-042156.890}

Background Cyclists are hard to be seen on the roads during night, rain, fog and hazy weather. Mostly these vehicles do not have any lights which could alert the other drivers to feel their presence on roads. They especially cyclist became almost invisible during the night when head lights from other side makes driver almost blind.

Description Most of the Indian population lives in rural areas and small cities. Walking and cycling remain the dominant modes of transport in small cities and rural areas. ${ }^{1}$ The pedal bicyclist constitutes a significant share of total traffic on Indian roads accounting for $15-35 \%$ of total trips. ${ }^{2}$ The incidence of head injuries in cyclists ranges from $14-36 \%$ of the total injuries.

Method We have chosen one district to make the cyclists visible on the roads. The focus is on the labour class especially and the students riding it to schools. We involved traffic police and media to make it success. We choose the spot where the labour and workers with cycles are stationed.We fix high quality reflective on the cycles to make it visible on roads. And also we guide them about the driving precautions to be observed on roads riding at night and during fog.

Results Aids to improve pedestrians and cyclist visibility have been used to avert potential collisionsVisibility aids have the potential to increase visibility and enable drivers to detect pedestrians and cyclists earlier."Fluorescent materials in yellow, red and orange colours improve detection and recognition in the daytime. Retroreflective materials enhance recognition.

Conclusions Policy making and its enforcement is most important part of any project and which bring success to the project finally. Indian cycle industry have clear directions on reflective issues under Bureau of Indian Standards .Despite several submissions to Government we are finally moving to the Court of Justice to make it mandatory for cycle manufacturing industry to maintain the standards of reflectors.

\section{NOTES}

1 Gururaj G. Bangalore: Aditi Enterprises; 2011. Road safety in India: A frame work for action copyright: NIMHANS.

2 Mohan D. Delhi: Indian institute of technology; 2004. The Road ahead traffic injuries and fatalities in India.

\section{ANIMAL-DRAWN VEHICLES: ESTABLISHING A NATIONAL 'RECOMMENDED PRACTICE' TO IMPROVE THEIR VISIBILTY ON ROADS}

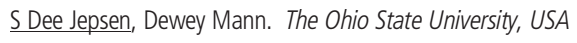

\subsection{6/injuryprev-2016-042156.891}

Background The horse is the main mode of transportation for Anabaptist populations and as a result, horse-drawn vehicles are involved in a high percentage of injury crashes with the motoring public. Members of the American Society of Agricultural and Biological Engineers established an Engineering Practice for animaldrawn buggies and wagons, and recently updated this Practice to include low-profile pony carts in 2014. The recommended 